\title{
ANÁLISE PLURAL DE LEITURAS DE ALUNOS E PROFESSORES DE UMA ESCOLA PÚBLICA
}

\author{
ANALYSIS OF PLURAL READINGS OF STUDENTS AND TEACHERS \\ AT A PUBLIC SCHOOL
}

\author{
Cleyde Nunes Pereira de Carvalho (UEMS) ${ }^{1}$ \\ Fátima de Lourdes Ferreira Liuti (UEMS) ${ }^{2}$
}

\begin{abstract}
Resumo: Este artigo é decorrente de uma pesquisa realizada, em 2003, em uma escola pública de ensino fundamental na cidade de Naviraí, estado de Mato Grosso do Sul, tendo como objetivo analisar as leituras de alunos e professores, e apresentar uma proposta para a formação de leitores. O conceito de leitura norteador da pesquisa foi o de LAJOLO, que dá ênfase ao leitor maduro, uma vez que este é o que a cada leitura desloca e altera o significado de tudo que já leu, tornando mais profunda sua compreensão dos livros, das gentes e da vida. Os recursos metodológicos utilizados foram: entrevistas, questionários, observações e o jornal de pesquisa. Este último recurso funciona como uma "técnica de desbloqueio", uma vez que consiste em escrever diariamente sem uma forma pré-determinada. $\mathrm{O}$ estudo demonstrou que os alunos são leitores, porém, imaturos. Os professores são leitores técnicos que buscam o livro para subsidiar suas aulas, ou para uma leitura informativa pertinente à sua profissão. $\mathrm{O}$ ambiente da biblioteca é precário, desestimulante e não oferece condições para a reflexão. A escola tem tomado iniciativas para melhorar o acervo da biblioteca e a maioria dos professores indica leituras de livros para seus alunos. Mas como na escola não há um programa que oriente as leituras de acordo com as diferentes faixas etárias, os alunos não conseguem ser alcançados de forma objetiva, impossibilitando sua maturidade de leitores. Enfim, as práticas de leituras não se relacionam de forma significativa ao processo ensinoaprendizagem.
\end{abstract}

Palavras-chave: Autonomia. Multirreferencialidade. Jornal de pesquisa. Formação de leitores.

Abstract: This article is the result of a survey conducted in 2003 in a public school elementary school in the city of Naviraí, state of Mato Grosso do Sul, aiming to analyze the opinions of students and teachers, and present a proposal for the formation readers. The

\footnotetext{
${ }^{1}$ Universidade Estadual de Mato Grosso do Sul - Especialista em Educação - cleyde.juina@hotmail.com

${ }^{2}$ Universidade Estadual de Mato Grosso do Sul - Doutora em Teoria de Literatura, Unidade Universitária de Naviraí-MS. fliuti@uems.br
}

\begin{tabular}{|l|l|l|l|l|l|}
\hline Interfaces da Educ. & Paranaíba & v. 2 & n. 5 & p.110-121 & 2011 \\
\hline
\end{tabular}




\section{INTERFACES DA EDUCAÇÃO}

concept of reading for directing the research was to Lajolo, which emphasizes the mature reader, since that is what each reading shifts and changes the meaning of everything I've read, making deeper und erstanding of his books, people and life. The methodology used were: interviews, questionnaires, observations and journal search. This last feature works as a "technical release" as it is to write every day without a pre-determined. The study showed that students are readers, but immature. Teachers are readers who seek technical support the book for their classes, or for reading information related to your profession. The library environment is poor, unattractive and does not provide conditions for reflection. The school has taken steps to improve the library collection and indicates most teachers reading books to their students. But as the school lacks a program to guide the readings according to different age groups, students can not be achieved in an objective manner, avoiding its mature readers. Finally, the practices of readings do not correlate significantly to the teaching-learning process.

Keywords: Autonomy. Multiple references. Journal research. training readers.

\section{Introdução}

A linguagem é uma das formas mais antigas de comunicação existentes no mundo, e há milênios tem sido usada como forma de inserção e exclusão social. Os homens mais antigos da história da civilização humana registraram-na em pedras, rochas e cavernas. Assim, gradativamente, surgiram a escrita e a leitura que consistem na interpretação desses símbolos.

A leitura é concebida pelo senso comum como a interpretação de símbolos alfabéticos e matemáticos, mas ambos carregados de sentidos e significados. Entretanto, em nosso país, há ainda muitos que não sabem decifrar esses símbolos. Contudo, talvez, ainda, mais grave do que isso, seja a realidade de muitos estudantes, em todos os níveis, que sabem decodificar, mas não interpretar. Não conseguem achar o sentido do que lêem, principalmente, se a ideia principal estiver nas entrelinhas do texto.

Nesse sentido, a leitura vincula-se ao conhecimento e o universo escolar fica com o grande compromisso de formar homens e mulheres para exercerem-se na sociedade contemporânea, e proporcionar um ambiente de aprendizagem, a fim de que não se corra o risco de sucumbir aos desejos da ideologia neoliberal e continuar aceitando a exclusão como algo natural.

Atualmente, existe um grande incentivo à prática da leitura, organizado em projetos escolares, propagandas em rádio, televisão e revistas. No entanto, quem convive no ambiente escolar constata que os resultados não têm sido muito promissores. Com poucas exceções, é público que as escolas enfrentam uma crise de leitura. Há um distanciamento dos alunos e não de poucos professores do ato de ler.

A afirmação baseia-se, principalmente, no desenvolvimento de uma pesquisa realizada em uma escola pública de ensino fundamental na cidade de Naviraí - Mato Grosso do Sul, com o objetivo de analisar as leituras de alunos e professores e apresentar uma proposta para a formação de leitores. Foram analisadas as leituras de seis docentes e três discentes de uma $8^{\mathrm{a}}$

\begin{tabular}{|l|l|l|l|l|l|}
\hline Interfaces da Educ. & Paranaíba & v. 2 & n. 5 & p.115-125 & 2011 \\
\hline
\end{tabular}




\section{INTERFACES DA EDUCAÇÃO}

série do período vespertino. Os recursos metodológicos utilizados foram: entrevistas, questionários, observações e o jornal de pesquisa. Este último recurso é muito difundido no Brasil através dos precursores da Multirreferencialidade. Mais adiante discorremos com detalhes sobre o Jornal de pesquisa.

\section{Os Alunos}

Os alunos sujeitos da pesquisa, na ocasião da entrevista, apresentavam idade entre 15 e 16 anos, sendo um do sexo masculino e duas do feminino. A profissão dos pais variava de tratorista, cozinheira, pedreiro, doméstica e do lar. No geral, declararam que em casa há pouco convívio com livros. $\mathrm{O}$ aluno declarou que raramente frequenta a biblioteca da escola ou consulta dicionários. Mostrou ser um leitor escolarizado, ou seja, lê apenas para atender às necessidades da escola. Diferente das alunas que já leram vários livros, frequentavam ocasionalmente a biblioteca da escola e, inclusive, a municipal. Mostraram ser leitoras para além da escola. Todos eles declararam que preferem livros com ilustrações e nenhum deles demonstrou maturidade para identificar a diferença entre o real e o ficcional num conto.

Os alunos não conseguiram estabelecer relação com as leituras propostas e a realidade que vivenciavam. Diante de um texto ficcional, tentaram dar explicações lógicas para o inexplicável. Para fazer as constatações utilizamos um conto de Roberto Drummond intitulado "O homem que subornou a morte". O texto literário apresenta a história de um milionário e sua namorada que são surpreendidos pela visita da "morte". Os protagonistas da história, Nando Paixão e Manuela, decidem, inicialmente, tentar enganar a morte com a desculpa da ausência dele no apartamento. Fracassado o plano inicial, optam por embebedá-la e, em seguida, tentam suborná-la, o que não foi fácil, já que ao oferecer férias em Nova Iorque, a morte recusou justificando que, além de não tirar férias, ela tinha "medo de avião". O milionário não desiste e oferece-lhe um milhão de dólares e mais um apartamento de cobertura em troca de mais vinte anos de vida. A conversa começa a interessar a morte, que em determinado momento do diálogo, confessa, já com certa intimidade, que "nunca havia tomado champanhe na vida". Ela pergunta se o dinheiro seria em dólares, o que é confirmado por Nando Paixão, e os dois fecham negócio. Porém, o protagonista engana a morte entregando-lhe dólares falsos em uma maleta estilo James Bond. Ele ficou tão alegre com a negociação, que chamou sua Manuela para dançar uma valsa. E o narrador arremata: "Estava tão alegre que morreu de felicidade".

Fizemos três perguntas sobre o texto e esperávamos que todos eles respondessem que se tratando de ficção tudo é possível. No entanto, tentaram, a todo o momento, dar um sentido real à ficção e achar justificativas para as ações dos personagens, sempre levando para o mundo real. Por mais absurdo e irreal que fossem os relatos da história, como por exemplo, a morte que toma champanhe e que tem medo de avião, mas que um dia fora viva - eles não separaram o real da ficção. A partir das alegações dos alunos foi possível inferir que os alunos sujeitos da pesquisa não são leitores maduros.

De acordo com Lajolo (1993, p.106) “o leitor maduro é aquele para quem a cada

\begin{tabular}{|l|c|c|c|c|c|}
\hline Interfaces da Educ. & Paranaíba & v. 2 & n. 5 & p.115-125 & 2011 \\
\hline
\end{tabular}


leitura desloca e altera o significado de tudo que já leu, tornando mais profunda sua compreensão dos livros, das gentes e da vida". Mas como avaliar as possibilidades significativas de um texto se o leitor nem o localiza como real ou ficcional?

Muitos fatores estão envolvidos nessa dinâmica, como o acervo bibliográfico da escola, o ambiente da biblioteca, a autonomia e as leituras dos professores e até a família. No decorrer do texto, discorreremos sobre esses fatores.

\subsection{Os professores}

O corpo docente da $8^{\mathrm{a}}$ série era composto por professores efetivos, com exceção da professora de Ensino Religioso que era contratada. Todos habilitados com curso superior, sendo que a maioria foram formados em universidades estaduais e federais.

Os professores demonstraram serem leitores técnicos que buscam o livro para subsidiar suas aulas, ou para uma leitura informativa pertinente à sua profissão. Essa constatação partiu das respostas dadas pelos professores entrevistados sobre as leituras que haviam realizado nos últimos meses. Foram poucas as leituras citadas e, em muitos casos, sem a lembrança do título do livro ou o nome do autor. As leituras dos professores entrevistados resumiram-se basicamente em periódicos, revistas, e-mails e livro didático.

Para formar leitores é necessário ser leitor. Segundo Lajolo $(1985$, p. 54) “o primeiro requisito para que o contato aluno/texto seja o menos doloroso possível é que o mestre não seja um mau leitor. Que goste de ler e pratique a leitura".

No entanto, todos demonstraram preocupação em avançar nos níveis de leitura, sobretudo para que esse avanço, naturalmente, tenha reflexo na sala de aula. Mas para isso, alguns obstáculos têm que ser vencidos, como por exemplo, a melhoria do ambiente da escola, sobretudo da biblioteca, afinal ela tem influência no alunado no que se refere à prática da leitura.

Embora a escola considere, em seu discurso, que a leitura é uma habilidade indispensável para o sujeito ser, de fato, ativo na vida em sociedade, conforme Amarilha (1999, p.11), "ela é negada na escola sem biblioteca, na sala de aula onde se vê destituída de seu valor social existencial e afetivo". Percebe-se que o ambiente da biblioteca é, muitas vezes, impróprio para leitura, por ser um espaço pequeno, sem ventilação e com acervo desinteressante. Em alguns casos o melhor material da escola é "sacralizado", ou seja, fica guardado em armários trancados, fora do ambiente da biblioteca, com a justificativa de se evitar o extravio. De fato, agindo assim a escola não corre o risco de perder o seu acervo e, muito menos, o de formar leitores.

\subsection{A biblioteca}

$\mathrm{Na}$ ocasião da visita à biblioteca escolar o cenário era este: alguns mapas em um mural, dois armários fechados à chave, uma mesa grande e três pequenas, um mimeógrafo quebrado e um velho ventilador rodando no teto, mas insuficiente para amenizar o calor. A

\begin{tabular}{|l|c|c|c|c|c|}
\hline Interfaces da Educ. & Paranaíba & v. 2 & n. 5 & p.115-125 & 2011 \\
\hline
\end{tabular}




\section{INTERFACES DA EDUCAÇÃO}

sala era pequena e pouco iluminada, mas o que mais chamou a atenção foram duas prateleiras de madeira cheias de livros de todo tipo, inclusive com muitas coleções de livros bem antigos, aproximadamente vinte coleções. Uma professora afastada das atividades de sala de aula cuidava da biblioteca. Ela informou que quando chegou à escola, a biblioteca estava desativada, então fez as devidas organizações e para melhorar o acervo, gravou fitas da programação da TV Escola chegando a um montante de 165 fitas de vídeo. Os conteúdos são de Geografia, Ciências, História, Educação Física, Filosofia, Meio Ambiente, Língua Portuguesa, Artes, Matemática, Inglês, Teleconferências, Literatura e outros.

A escola organizou um projeto que objetivava a ampliação do acervo da biblioteca. Tratava-se de uma gincana cultural, por meio da qual os alunos do Ensino Fundamental e Médio tinham que arrecadar livros, pedindo nas residências, a equipe que fizesse a maior coleta ganharia troféus, medalhas e uma viagem. O projeto contava com a participação de professores, em especial, de Língua Portuguesa e Artes, Direção e Coordenação.

Os clássicos literários para jovens não ficavam na biblioteca, eles estavam guardados em outra sala e somente os professores tinham acesso a eles. A professora informou que não havia controle dos empréstimos e devoluções desses livros.

Ficou muito claro a disposição e o empenho da professora que atuava na biblioteca e da equipe gestora em melhorar o ambiente da escola, principalmente o da biblioteca. Porém, o que estava faltando era um programa eficiente de organização do acervo, de acordo com as diferentes faixas etárias. Amarilha (1999) nos aduz sobre a necessidade dos alunos passarem por um processo de gradação em leitura, ou seja, para leitores em fase de alfabetização é aconselhável livros com muitas ilustrações e poucas páginas, mas gradativamente deve-se ir apresentando livros com menos gravuras e mais páginas. Segundo ela, a ênfase às ilustrações não permite que o leitor mirim se desenvolva, formando assim, leitores de livros com competências somente para livros ilustrados, pois "a prática do contato com o livro proporcionado pela escola acrescenta muito pouco ao desenvolvimento do leitor, acaba se tornando um simples manusear de livros, sem desenvolver, simultaneamente, o interesse e as habilidades de leitura". (AMARILHA, 1999, p. 40).

A autora vai mais além, considera essa atitude do professor como uma omissão quanto aos estágios de desenvolvimento da criança. Afinal, ela precisa ganhar autonomia, e, assim, torna-se imprescindível a intervenção de um profissional que oriente para outros níveis de leitura. Faz-se, portanto, necessária a prática gradual, mas persistente da leitura de textos mais longos, ao invés do uso das ilustrações e do texto breve. Dessa forma, na fase adulta o leitor estaria pronto para enfrentar com prazer a leitura de um longo livro, sem ilustrações.

\section{Concepções de leitura e de leitores}

Partimos da concepção do ato de ler como prática que possibilite ao indivíduo a aquisição de habilidades para tornar-se um sujeito ativo na vida em sociedade, apropriando-se da cultura e dos valores que lhe são de direito. Ou seja, a leitura para além da mera decodificação, oposta à simples decifração da escrita. Segundo Martins (1988, p. 23), "ler

\begin{tabular}{|l|l|l|l|l|l|}
\hline Interfaces da Educ. & Paranaíba & v. 2 & n. 5 & p.115-125 & 2011 \\
\hline
\end{tabular}




\section{INTERFACES DA EDUCAÇÃO}

significa interar-se do mundo, sendo também uma forma de conquistar autonomia, de deixar de ler pelos olhos de outrem".

Atualmente, a leitura é amplamente incentivada em todos os âmbitos da sociedade, sobretudo, na escola. Contudo, ela não se tornou ou parece não se constituir uma prática efetiva na vida dos estudantes brasileiros. De forma geral, falta-lhes reflexão, ou seja, meditação, discernimento, consideração atenta.

De acordo com Castro (2002, p. 20), diante de um texto os alunos "decifram a idéia central e passam a divagar sobre o que pensam, sobre o que o autor poderia estar pensando, sobre o que evoca o texto". Assim, a interpretação fica mais a cargo da fantasia e imaginação. A conclusão é que os alunos leem como poetas e não como cientistas. Porém, devemos considerar que a leitura pode ser concebida como uma atividade puramente individual. Ela também precisa ser assumida na sua relação entre o cultural e a liberdade relativa do leitor de estabelecer significações, portanto, entre o uso social da leitura e a forma particular de apropriação do texto.

\subsection{Leitor escolar}

Resumindo as palavras de Batista (1998, p. 31), uma caracterização possível dada para alunos e professores é o de leitor "escolar", ou seja, em todas as suas leituras, até nas atividades não diretamente voltadas para escola e para a prática docente, tende-se a investir nas competências e nas disposições escolares, adquiridas escolarmente. Dessa forma, o leitor não se sente autorizado a se apropriar de suas leituras de forma autônoma, e essa falta de validação culmina numa resistência a essa prática. Normalmente, esse aluno ou professor lê o suficiente apenas para atender às necessidades da escola, dados constatados em nossa pesquisa.

O professor tem um papel fundamental na construção da autonomia da aprendizagem do aluno. Mas afinal, o que é autonomia?

\footnotetext{
Autonomia, etimologicamente (do grego autos, 'próprio', 'a si mesmo', e nomos, 'lei', 'norma'), na cultura grega, há 27 séculos, significava a capacidade de a cidade (polis) se autogovernar, de elaborar suas próprias leis, de ter moeda própria e, consequentemente, a recusa à subjugação a um rei, a um tirano, ou déspota. Seria a afirmação, portanto, da cidadania, da liberdade, e a negação da submissão (PRETI, 2005 , p. 112, grifos do autor).
}

A autonomia se adquire gradualmente. O professor deverá respeitar o tempo de cada aluno na construção de suas leituras. O tempo é muito subjetivo, cada um tem o seu próprio tempo.

A escola deve conduzir o aluno para ser um autodidata, construir o seu conhecimento através das leituras. De acordo com Preti (2005, p. 116), "para que isso aconteça exige-se tomada de decisão, 'desacomodação', desafios, lutas, renúncias, responsabilidade e engajamento." Do contrário, esse aluno será apenas um agente passivo de informações.

\begin{tabular}{|l|c|c|c|c|c|}
\hline Interfaces da Educ. & Paranaíba & v. 2 & n. 5 & p.115-125 & 2011 \\
\hline
\end{tabular}




\section{INTERFACES DA EDUCAÇÃO}

Assim, a autonomia está diretamente relacionada à questão da leitura, afinal não se forma leitor sem proposições de leitura. O professor que fala com entusiasmo de suas leituras, terá mais chances de formar alunos leitores desejantes dessa prática tão prazerosa e inclusiva. Mas não é só isso, a leitura precisa ser pensada na escola sob o ângulo do ensino e da aprendizagem. O professor precisa ter domínio sobre aquilo que ensina. $\mathrm{Na}$ escola não cabe apenas a virtude do exemplo, é preciso e necessário trabalhar a leitura também pedagogicamente.

No entanto, é real a constatação de que muitos alunos e não poucos professores lêem apenas textos de livros didáticos. Lajolo adverte:

Tudo o que chega à escola via livro didático - da data do descobrimento do Brasil à dimensão paródica das obras de Oswald de Andrade - parece tornar-se inquestionável. Transforma-se numa verdade absoluta, e duvidar dela ou discuti-la costuma, em muitos casos, refletir-se negativamente na avaliação do aluno. Ao endossar as tais verdades absolutas, ao assumir-se como guardião delas, o professor corre o risco de contribuir para a alienação do processo educativo (LAJOLO, 1985, p. 54).

O professor guiado apenas pelo livro didático acaba se tornando um mero agente transmissor de informações entre o autor do livro e os alunos.

Por último, de acordo com Batista (1998, p. 36), a caracterização do leitor "herdeiro", como aquele que apresenta habilidades relacionadas à leitura para além da escola. Ele recebeu um aprendizado pela familiarização, ou pela virtude do exemplo. O fato de ver os pais lendo livros, jornais, revistas, desenvolve na criança um aspecto de naturalidade. Assim, querer ser igual ao pai ou a mãe é, naturalmente, ler livros. No entanto, é importante ressaltar que a leitura não é somente um ato natural, é cultural e precisa ser aprendida.

\section{Autonomia na educação}

A autoridade precede a autonomia. Não há como ser autônomo sem ter autoridade. Não se trata de autoritarismo, e sim de práticas democráticas permeadas pela competência do docente, pela firmeza com que atua, pelo respeito às ideias dos discentes, pela segurança com que decide, pela sabedoria de ouvir o outro e de rever-se constantemente. O professor democrático, ao contrário do autoritário, sabe dar liberdade ao aluno para expressar suas opiniões, ainda que contrárias as deles, pois jamais minimiza a liberdade. Ele sabe que o educando, na medida em que exercita a sua liberdade, rompe com o silêncio e sente-se na obrigação de assumir a responsabilidade de suas ações. De acordo com o educador Paulo Freire,

um esforço sempre presente à prática da autoridade coerentemente democrática é o que a torna quase escrava de um sonho fundamental: o de persuadir ou convencer a liberdade de que vá construindo consigo mesma, em si mesma, com materiais que, embora vindo de fora de si, sejam reelaborados por ela, a sua autonomia. É com ela, a autonomia, penosamente construindo-se, que a liberdade vai preenchendo o 


\title{
INTERFACES DA EDUCAÇÃO
}

'espaço' antes 'habitado' por sua dependência. Sua autonomia que se funda na responsabilidade que vai sendo assumida. [...] No fundo, o essencial nas relações entre educador e educando, entre autoridade e liberdades, entre pais, mães, filhos e filhas é a reinvenção do ser humano no aprendizado de sua autonomia (FREIRE, 1998, p. 105).

Autonomia para pensar, decidir, agir, mas uma autonomia permeada pela ética, pela verdade, pela sensatez, por um discurso verdadeiro de quem fala e vive o que diz. Não se permite mais a exclusão, a dominação em nome da liberdade. Assim, a educação deve ser uma prática mobilizadora da verdade, da busca por uma sociedade mais justa, mais inclusiva, mais tolerante, mais igualitária e mais democrática. Nessa perspectiva, o professor não pode ser apenas um repassador de conteúdos, alguém indiferente às questões que o rodeia, um sujeito que não conhece seus direitos e deveres, ou seja, um cidadão alienado. Freire nos encanta com suas palavras ao falar de si mesmo como professor. Vejamos:

Sou professor a favor da decência contra o despudor, a favor da liberdade contra o autoritarismo, da autoridade contra a licenciosidade, da democracia contra a ditadura de direita ou de esquerda. Sou professor a favor da luta constante contra qualquer forma de discriminação, contra a dominação econômica dos indivíduos ou das classes sociais. Sou professor contra a ordem capitalista vigente que inventou esta aberração: a miséria na fartura. Sou professor a favor da esperança que me anima apesar de tudo. Sou professor contra o desengano que me consome e imobiliza (FREIRE, 1998, p. 115).

Uma das funções primordiais do professor é formar cidadãos. Essa formação não se dá da noite para o dia. Ela acontece aos poucos, nas inúmeras experiências e decisões que vão sendo tomadas cotidianamente. Preti esclarece:

\begin{abstract}
Autonomia não se situa no campo metafísico, da especulação; não é um componente do real, aí posto naturalmente, ou um objeto de contemplação. Não é uma qualidade humana que nos foi outorgada ou oferecida mediante decreto-lei: “'Cumpra-se!' A partir de agora, o cidadão, a escola e o professor têm sua autonomia!" É uma qualidade produzida, construída pelo homem a duras penas: a capacidade de decidir o que fazer e como fazer, de dar "intencionalidade" e direção às ações (PRETI, 2005, p. 115, grifos do autor).
\end{abstract}

Ainda, de acordo com o autor, a autonomia deve ser construída numa prática fundamentada em um projeto de vida e de trabalho. É um projeto de natureza política, de natureza social, ao mesmo tempo individual e coletivo.

Atualmente, por conta do avanço acelerado do conhecimento, a educação tem que ser voltada para a autonomia do aprendiz, ou seja, a autonomia passou a ser um dos ideais da ação educativa. Não se concebe mais um professor apenas repassador de conhecimento e nem um aluno passivo, que não seja capaz de fazer a leitura do mundo que o circunda. Sobretudo, quando a todo o momento descobre-se algo novo, surgem novas teorias, muitas delas

\begin{tabular}{|l|c|c|c|c|c|}
\hline Interfaces da Educ. & Paranaíba & v. 2 & n. 5 & p.115-125 & 2011 \\
\hline
\end{tabular}




\section{INTERFACES DA EDUCAÇÃO}

contradizendo outras ou revelando fatos que entram em desacordo com crenças e valores. Nesse momento, o sujeito precisa ter aprendido a questionar o mundo que o rodeia e, também, a questionar-se.

Assim, é de fundamental importância que o professor acredite em mudanças, que não seja um resignado que diga: “o mundo é assim e sempre será. Eu nada posso fazer!". Seu trabalho não pode ser a favor da exclusão, da dominação. No entanto, as mudanças devem acontecer com ordem, afinal, autonomia é, sobretudo, um assumir de responsabilidades compartilhadas. Nesse sentido, formar leitores críticos passa a ser uma prioridade para o professor.

\section{Jornal de pesquisa}

A sociedade vê a escola como a grande responsável por formar estudantes desejantes da prática da leitura, mas o que temos visto e vivenciado é uma dificuldade de leitura e escrita em todos os níveis. Não há produção e sim, reprodução mecânica para atender às atividades da escola. Não resta dúvida de que novas propostas devem-se desencadear no cotidiano escolar como alternativa para reverter esse quadro. Afinal, como afirma Neves (1999), o ato de ler não é decorrência de uma habilidade inata, ou melhor, não é um dom com o qual o indivíduo nasce e morre, tais como a respiração, a sucção, a fala, os movimentos e outras funções vitais. $\mathrm{O}$ ato de ler precisa ser ensinado.

Nesse sentido, apresentamos uma proposta de leitura e produção de texto que pode ser implementada em diferentes níveis de ensino. Trata-se da utilização do "Jornal de Pesquisa", um instrumento metodológico difundido no Brasil pelos teóricos precursores da Multirreferencialidade. Esta abordagem é de origem relativamente recente, somente no ano de 1997 foi publicado, no Brasil, o primeiro livro tratando do assunto, de autoria de Sérgio da Costa Borba. No entanto, nas décadas de 1980 e 1990 já havia alguns professores fazendo esse percurso intelectual. A Multirreferencialidade teve origem na França e profissionais como René Barbier, Alain Colon e Jacques Ardoino visitaram o Brasil para estabelecer contato e promover sua divulgação em nosso meio.

Os autores conceituam a Multirreferencialidade como a leitura plural dos fatos, das práticas, das situações e dos fenômenos educativos a partir de diferentes ângulos, em função de sistemas de referências distintos e não redutíveis uns aos outros. Segundo Borba (1998, p.12), "uma leitura plural supõe a quebra de fronteiras disciplinares, a quebra da monorracionalidade na compreensão, análise, explicação, construção do objeto. A Multirreferencialidade é um hino contra o reducionismo. Um hino ao esforço da liberação humana." O "Jornal de Pesquisa" originou-se dessa perspectiva. O professor Joaquim Gonçalves Barbosa (2000) registrou em um de seus livros detalhes sobre o "Jornal de Pesquisa" aplicado como metodologia de formação de pesquisadores.

Num primeiro momento, o "Jornal de Pesquisa" pode ser visto como um diário, no qual o pesquisador registra o seu cotidiano de forma livre e espontânea. Sua principal preocupação não deve ser com a ortografia, mas, sim, com o registro de impressões, ou seja,

\begin{tabular}{|l|c|c|c|c|c|}
\hline Interfaces da Educ. & Paranaíba & v. 2 & n. 5 & p.115-125 & 2011 \\
\hline
\end{tabular}




\section{INTERFACES DA EDUCAÇÃO}

algo que leve o sujeito à reflexão, pois esse material deverá retornar ao leitor-pesquisador, fornecendo dados para sua pesquisa. Contudo, não deve ficar na perspectiva de um diário íntimo, uma vez que, pode ser lido diariamente por outras pessoas, funcionando como um jornal de domínio público. Este instrumento permite que o seu autor registre o caminho percorrido na pesquisa, suas angústias, dificuldades, inseguranças e tensões provocadas pelo processo de escrita. Assim, depois do texto pronto e acabado, é permitido olhar para trás e conhecer o processo de construção de sentidos durante todo o percurso. Esse processo foi experimentado por Liuti (2001), no período em que desenvolveu sua pesquisa de Mestrado e por Carvalho (2003) na realização desta pesquisa.

Vale lembrar, que o "Jornal de Pesquisa" pode ser aplicado para alunos do ensino fundamental, médio, superior e demais níveis. No campo de pesquisa educacional, o "Jornal de Pesquisa" é um recurso recente e, portanto, passível de polêmica, sobretudo porque rompe com a tradição do pesquisador preso a um único padrão metodológico. Porém, esse recurso permite a leveza da escrita, uma vez que estimula o desejo de escrever de forma não normativa, sem cobranças, sem censuras que inibem e inviabilizam a leitura mais solta da situação prática que pode ser alienante. Enfim, os resultados demonstram que com esse instrumento a leitura e a produção escrita tornam-se fonte de prazer, expressão, trabalho de reflexão, comunicação e interação.

\section{Considerações finais}

A escola pesquisada passa por uma crise de leitura decorrente da não-formação de leitores assíduos e maduros. Não há programas estabelecidos que orientem as leituras que deveriam ser oferecidas aos alunos desde a fase pré-escolar até o ensino médio. Assim, os professores seguem uma linha individual, mas que não alcança a todos os alunos de forma objetiva.

Há a disposição dos profissionais da escola para aumentar o acervo da biblioteca, mas falta-lhes o embasamento teórico-metodológico para saber lidar com a situação, ou seja, organizar o acervo de acordo com as diferentes faixas etárias, atentar para que o ambiente da biblioteca proporcione condições para a reflexão. É necessário, ainda, registrar de uma forma mais eficaz a entrada e saída de livros emprestados pelos alunos e professores, bem como os eventos que ela promove, e outras necessidades que visem dinamizar o funcionamento da biblioteca.

O incentivo à leitura, normalmente, alcança apenas aqueles que já têm uma propensão à leitura advinda dos familiares ou outros meios alheios à escola. Os professores, em sua maioria, são leitores escolarizados, ou seja, tem suas leituras direcionadas pelo livro didático ou por textos que subsidiam suas aulas.

A falta de autonomia dos professores refletida por algumas ações, como a utilização da leitura apenas para repassar conhecimentos advindos, em sua grande maioria, do livro didático, pode culminar em um desinteresse pela leitura em sala de aula, como se ela fosse desnecessária e dispensável. Formar leitores com o livro didático é uma missão quase

\begin{tabular}{|l|c|c|c|c|c|}
\hline Interfaces da Educ. & Paranaíba & v. 2 & n. 5 & p.115-125 & 2011 \\
\hline
\end{tabular}




\section{INTERFACES DA EDUCAÇÃO}

impossível. Para se obter sucesso nessa tarefa é necessário o oferecimento de livros que levem o leitor a reconhecer-se nele, ou talvez, a reconhecer algo de sua história de vida passada ou presente, ou, ainda, identificar ou negar naquele livro costumes de seus pais, parentes ou filhos. Quando o leitor descobre que o livro que lê, inquieta, desconforta, revela e acrescenta coisas do mundo, nesse momento, formou-se um leitor.

A quantidade diminuta de computadores, livros, revistas e jornais, também são grandes responsáveis pelo fracasso em relação à formação de leitores. Porém, o despertar para a sua necessidade é que validará a sua aquisição, haja vista a autonomia que as escolas ganharam com a gestão democrática implementada nos últimos anos.

A pesquisa aponta para uma reflexão acerca da formação dos professores. Os que já atuam como profissionais devem buscar maiores qualificações por intermédio dos programas de pós-graduação e formação continuada. A escola precisa equipar-se com mais computadores conectados à internet, multimídia e laboratórios que fiquem à disposição dos alunos e professores. Para se oferecer um ensino de qualidade e atrair leitores implica, no mínimo, dotar a escola de uma biblioteca com acervo completo e atualizado.

Nesse aspecto, a formação de leitores, muito longe de ser marginal ou subsidiária, deve ser construída por meio de uma ação conjunta, solidária, entre família, pela virtude do exemplo, escola, professores e alunos. A escola tem o compromisso de oferecer educação para a inclusão, possibilitando que todos possam dele participar como autores. Considerandose que nesse processo de apropriação, invenção e produção de significados da leitura há discursos que atravessam a escola e, que de certa forma, prescrevem os modos de ler.

\section{Referências Bibliográficas}

AMARILHA, M. (Org.) Educação e Leitura. Natal: Editora da UFRN, 1999. Estão mortas as fadas? Natal: Editora da UFRN, 2001.

ARDOINO, J. Abordagem Multirreferencial (plural) das situações educativas e formativas. Tradução de Rosângela Batista de Camargo. In: BARBOSA, J. G. Multirreferencialidade nas ciências e na educação. São Carlos: EdUFScar, 1998.

BARBOSA, J. G. A sala de aula como espaço de formação e produção do conhecimento. In: BARBOSA, J. G. (Org.). Autores-cidadãos: a sala de aula na perspectiva multirreferencial. São Paulo: EdUFScar, EdUMESP, 2000.

BATISTA, A. A. G. Os (as) professores (as) são não-leitores? In: MARINHO, M. (Org.). Leituras do professor. Campinas, São Paulo: Mercado das Letras, 1998.

BORBA, S. C. Aspectos do Conceito de Multirreferencialidade nas ciências e nos espaços de formação. In: BARBOSA, J. G. (Org.). Reflexões em torno da abordagem Multirreferencial. São Carlos: EdUFSCar, 1998.

CASTRO, C. M. O Brasil lê mal. Veja, São Paulo, Ponto de Vista, 6 mar. 2002.

FREIRE, P. Pedagogia da autonomia: Saberes necessários à prática educativa. Rio de Janeiro: Paz e Terra, 1998.

\begin{tabular}{|l|c|c|c|c|c|}
\hline Interfaces da Educ. & Paranaíba & v. 2 & n. 5 & p.115-125 & 2011 \\
\hline
\end{tabular}




\section{INTERFACES DA EDUCAÇÃO}

DRUMMOND, Roberto. O homem que subornou a morte. Porto Alegre: Mercado Aberto, 1999, 71-77.

LAJOLO, M. Do mundo da leitura para a leitura do mundo. S. Paulo: Ática, 1993. (Série Educação em Ação).

O texto não é pretexto. In: ZILBERMAN, R. (Org.). Leitura em crise na escola: as alternativas do professor. Porto Alegre: Mercado Aberto, 1985.

LIUTI, F.de L. F. O Terreno Pantanoso da Leitura e Cidadania: estudo sobre uma escola pública de Naviraí-MS. Dissertação (Mestrado em Fundamentos da Educação) - Centro de Educação e Ciências Humanas. São Paulo: Universidade Federal de São Carlos, 2001.

MARTINS, M.H. O que é leitura. S. Paulo: Brasiliense, 1988.

NEVES, I. C. B. Ler e escrever na biblioteca. In: BITENCOURT, I. C. (Org.). Ler e escrever: Compromisso de todas as áreas. Porto Alegre: Ed. Da Universidade/UFRGS, 1999.

PRETI, O. A “Autonomia” do estudante na educação à distância: Entre concepções, desejos, normatizações e práticas. In: PRETI, O. (Org.). Educação a Distância: sobre discursos e práticas. Brasília: Líber Livro Editora, 2005.

\begin{tabular}{|l|l|l|l|l|l|}
\hline Interfaces da Educ. & Paranaíba & v. 2 & n. 5 & p.115-125 & 2011 \\
\hline
\end{tabular}

